\title{
Effect of high sucrose diet on insulin secretion and insulin action. A study in rats with non-insulin-dependent diabetes induced by streptozotocin
}

\author{
M. Kergoat, D. Bailbe and B. Portha \\ Laboratory of Development Physiology, University of Paris, Paris, France
}

\begin{abstract}
Summary. The effects of chronic high sucrose feeding for 1 month on in vivo and in vitro insulin secretion and on in vivo insulin action were studied in rats with non-insulin-dependent diabetes. As compared to the standard diet, the high sucrose diet induced an increase of the in vivo insulin response to an intravenous load and deteriorated the glucose tolerance as attested by significantly lower rates of glucose disppearance ( $\mathrm{K}$ values, $p<0.001$ ). The increased insulin secretion in response to glucose in vivo seems to be related to a slight increase of the pancreatic B-cell reactivity to glucose, since it was still observed in vitro with the isolated perfused pancreas preparation. By contrast, B cells of sucrose-fed rats exhibited in vitro a significantly lowered $(p<0.01)$ response to acetylcholine and arginine. The insulin action in the sucrose-fed diabetic rats was quantified in vivo with the insulin-glucose clamp technique. The effects of different concentrations of insulin on glucose production and glucose utilisation were studied in anaesthetized rats while in the postabsorptive state. The basal glucose utilisation was found significantly higher $(p<0.001)$ in sucrose-fed rats. During the clamp studies the glucose utilisation induced by submaximal $(450 \mathrm{mU} / 1)$ insulin level was significantly less important
\end{abstract}

$(p<0.01)$ in the sucrose-fed rats than in the chow-fed rats. Following a maximal hyperinsulinaemia $(5000 \mathrm{mU} / 1)$ the glucose utilisation was similar in both groups. This suggests that insulin-mediated glucose uptake is decreased over the range of submaximal plasma insulin levels in the sucrose-fed diabetic rats. In the basal state hepatic glucose production was significantly higher $(p<0.001)$ in sucrose-fed rats. During the clamp studies, the suppression of glucose production induced by submaximal or maximal insulin levels was significantly less effective $(p<0.01)$ in the sucrose-fed rats as compared to chow-fed rats, thus suggesting that the liver becomes resistant to insulin action after sucrose feeding. Finally, these results suggest that restriction of complex carbohydrates in favor of sucrose in insulin-deficient rats leads to metabolic events likely to develop insulin resistance in target tissues.

Key words: High sucrose feeding, rats with non-insulin-dependent diabetes, insulin secretion, perfused pancreas, insulin action, insulin-glucose clamp technique, glucose production, glucose utilisation.
The sucrose content of the diet has a major effect on glucose tolerance and insulin secretion in humans as well as laboratory animals. It is well established that sucrose feeding markedly increases basal insulin levels as well as glucose-stimulated insulin release $[10,16,19$, $22,24,25,27,35,36,40,43,44]$. However, the influence of this particular type of diet on glucose tolerance is not as clear. Glucose tolerance after a period of sucrose feeding has been reported to be either improved $[10,26,35,40,43]$, unchanged [16] or even deteriorated $[8,19,25,37,38,44]$. Explanations for these apparently conflicting results may lie at the level of differences in the relative proportions of carbohydrates, fat and proteins in the diets, total carbohydrate concentration or total sucrose concentration. It may also depend on the palatability of the various diets, and on whether they induced hyperphagia and/or obesity. Reinvestigating this problem, we have recently shown that when normal Wistar rats are offered a high sucrose diet, the glucose tolerance is significantly improved and the insulin-mediated glucose utilisation is increased in vivo under the conditions of the insulin-glucose clamp technique, thus suggesting an increased insulin sensitivity of peripheral tissues [22].

Patients with diabetes have been encouraged to avoid adding sucrose to their diets until recently. However, this point of view seems to be changing, and recent dietary recommendations have indicated that modest amounts of sucrose may be incorporated into meals for diabetic patients [1]. The justification for this change in dietary advice appears to be based upon studies in which the plasma glucose response to single 
meals was not accentuated when sucrose was incorporated into the meal $[2,3,6,31,32]$. Preliminary studies from our laboratory have shown that in rats with noninsulin-dependent diabetes induced by streptozotocin [34], sucrose feeding did not improve glucose tolerance [35], at variance with the effect reported in normal rats $[22,35]$. It was therefore decided to reinvestigate this question and to determine the effect of high sucrose feeding in rats with non-insulin dependent diabetes on: (1) glucose tolerance (2) in vivo and in vitro glucose-induced insulin release (3) basal and insulin-stimulated in vivo glucose production and glucose utilisation, using the insulin-glucose clamp technique in conjunction with isotopic measurement of glucose turnover.

\section{Materials and methods}

\section{Animals and diets}

On the day of their birth, male Wistar rats bred in our own colony received streptozotocin (STZ $100 \mu \mathrm{g} / \mathrm{g}$ ) in $25 \mu \mathrm{l}$ citrate buffer $(0.05 \mathrm{~mol} / \mathrm{l}), \mathrm{pH} 4.5$, through the saphenous vein made directly accessible by transcutaneous puncture as previously described [33]. The litters were limited to eight. Four days after birth, all the neonates exhibited glycosuria reaching $3+$ Clinistix values (Ames, Division Miles Laboratories, Paris, France). Spontaneous evolution of this neonatal diabetes led to a non-insulin-dependent diabetic state in the adult which was stable and chronic as previously described [34]. The animals were weaned 21 days after birth with free access to a commercial pelleted chow (No.113, UAR, Villemoissons/Orge, France).

At 6 weeks, after being given a glucose tolerance test, the rats were randomly divided into two groups: one group was maintained on the standard rat chow containing by weight $(\mathrm{g} / 100 \mathrm{~g}): 57 \%$ carbohydrate ( $4 \%$ cellulose), $5 \%$ lipid and $22 \%$ protein, and by calories: $61 \%$ carbohydrate, $13 \%$ lipid and $26 \%$ protein. The other group consumed a high sucrose diet containing by weight (g/100 g): $62 \%$ carbohydrate ( $7 \%$ cellulose), $4 \%$ lipid (maize oil) and $23 \%$ protein, and by calories: $63 \%$ sucrose, $10 \%$ lipid and $27 \%$ protein. Energy content by $100 \mathrm{~g}$ diet was the same ( 345 calories) in both groups. After being fed the respective diets for 3 weeks, some animals randomly selected by each group were given a glucose tolerance test; one week later (at 10 weeks of age) their pancreases were isolated and the insulin secretion was tested in vitro. The animals left in each group were used after 4 weeks on the diet (10 weeks of age) for measurement of in vivo insulin action using the glucose-insulin clamp technique.

By choosing the above protocol, we have compared rats fed either a commercial rat chow with a semi-synthetic sucrose diet. Moreover, while these two diets have a similar gross composition of protein and fat, one cannot ascertain that they do not differ with regard to the vitamin and mineral content. In order to take into consideration the possibility that the chow diet should not be the correct control diet for the sucrose diet, we performed pilot experiments with a batch of diabetic rats fed a semi-synthetic diet similar to that used, in which the sucrose was replaced by starch. The control semi-synthetic diet contained by weight ( $\mathrm{g} / 100 \mathrm{~g}): 59 \%$ starch (4\% cellulose), $4 \%$ lipid (maize oil) and 18\% protein, and by calories: $67 \%$ carbohydrate, $11 \%$ lipid and $22 \%$ protein. Both semi-synthetic diets contained the same salt mixture $(3.5 \mathrm{~g} / 100 \mathrm{~g})$ and vitamin mixture $(2.2 \mathrm{~g} / 100 \mathrm{~g})$.

In $\mathrm{mg} / \mathrm{g}$ of vitamin mixture there were:

folic acid 0.094 , biotin 0.047 , vitamin A $469 \mathrm{UI}$, cholecalciferol $94 \mathrm{UI}$, menadione 0.469 , thiamin 0.703 , riboflavin 0.703 , pyridoxine 0.469 , calcium pantothenate 2.344 , niacine 2.344 , p-aminobenzoic acid 14.062, inositol 23.437, $\alpha$-tocopherol 14.1 UI, choline 93.747, vitamin B-12 0.0023 and cellulose to make $1 \mathrm{~g}$.
In $\mathrm{g} / \mathrm{kg}$ of salt mixture, there were:

$\mathrm{CaHPO}_{4} 500 ; \mathrm{NaCl} 74 ; \mathrm{K}_{3} \mathrm{C}_{6} \mathrm{H}_{5} \mathrm{O}_{7}, \mathrm{H}_{2} \mathrm{O} 220 ; \mathrm{K}_{2} \mathrm{SO}_{4} 52 ; \mathrm{MgO} 24$; $\mathrm{MnCo}_{3} 3.5 ; \mathrm{FeC}_{6} \mathrm{H}_{5} \mathrm{O}_{7}, \mathrm{H}_{2} \mathrm{O} 6 ; \mathrm{ZnO} 1.6 ; \mathrm{CuCO}_{3}, \mathrm{Cu}\left(\mathrm{OH}_{2}\right) 0.3 ; \mathrm{KIO}_{3}$ $0.01 ; \mathrm{NaSeO}_{3}, 5 \mathrm{H}_{2} \mathrm{O} \quad 0.01 ; \mathrm{CrK}\left(\mathrm{SO}_{4}\right)_{2}, 12 \mathrm{H}_{2} \mathrm{O} 0.55$ and sucrose to make $1 \mathrm{~kg}$.

After feeding the semi-synthetic control diet for 3 weeks, the rats were given a glucose tolerance test. Results obtained in that group were not found significantly different from those obtained in the group maintained on the commercial chow, as far as daily food intake, weight gain over the 3 -week period, basal plasma glucose and insulin, rate of glucose disappearance (K) during the glucose tolerance test, incremental plasma glucose values and incremental plasma insulin values are concerned (data not shown). These results provide the evidence that diabetic rats fed the chow diet behave similarly to rats maintained on a semi-synthetic starchy diet. Thus, for the sake of simplification, the results presented in the present paper and obtained with diabetic rats fed the high sucrose diet were directly compared to results obtained in diabetic rats fed the chow diet.

\section{Glucose tolerance tests}

Intravenous glucose tolerance tests $(2.8 \mathrm{mmol}$ glucose $/ \mathrm{kg}$ body weight) were performed in the non-fasted state under pentobarbital anaesthesia ( $4 \mathrm{mg} / 100 \mathrm{~g}$ body weight intraperitoneally). Blood was withdrawn from the tail vein. Blood samples $(300 \mu \mathrm{l})$ were immediately centrifuged at $4{ }^{\circ} \mathrm{C}$ and plasma was stored at $-20^{\circ} \mathrm{C}$ until assayed.

\section{Insulin-glucose clamp studies}

These studies were performed at 14.00 hours in rats fasted from 09.00 hours according to a previously detailed procedure [21]. In these conditions, the rats were considered to be in the post-absorptive period; the rate of glucose production was a measure of endogenous glucose production. Rats were anaesthetized with pentobarbital. Body temperature was maintained at $37-38{ }^{\circ} \mathrm{C}$ with heating lamps. One carotid artery was catheterised for blood sampling and a tracheotomy was systematically performed to avoid respiratory problems during anaesthesia. A $150 \mu$ blood sample was collected $20 \mathrm{~min}$ after the end of the surgery for the determination of basal blood glucose and plasma insulin concentrations. In the diabetic rats maintained on the sucrose diet, an insulin solution was then infused at a constant rate of $20 \mu \mathrm{l} / \mathrm{min}$ in a saphenous vein, and the blood glucose level was clamped at the level measured in the basal state by a variable infusion of glucose through the other saphenous vein with a Precidor pump (Infors, Basel, Switzerland). The insulin dose-response curves were obtained by infusing various amounts of insulin $\left(0.6-3.2 \mathrm{U} \cdot \mathrm{h}^{-1} \cdot \mathrm{kg}^{-1}\right)$ to raise the plasma insulin levels to 400-5000 mU/1 values. Insulin (porcine monocomponent insulin Actrapid, Novo, Copenhagen, Denmark) was dissolved in $0.9 \%$ $\mathrm{NaCl}$ containing $0.2 \%$ bovine serum albumin (Sigma, St. Louis, Mo., USA). The infusion of exogenous glucose $(10 \%-20 \%$ solution) was begun $5 \mathrm{~min}$ after the initiation of insulin. $25 \mu \mathrm{l}$ of blood were then sampled from the carotid artery every $5 \mathrm{~min}$, and plasma glucose concentrations were determined within $60 \mathrm{~s}$ with a glucose analyzer (Beckman, Palo Alto, Calif., USA).

Since hyperglycaemia is known to enhance glucose metabolism by a mass action effect in the rat [21] as well as in the dog [7] and the human [14], the diabetic rats maintained on the standard chow were studied with a hyperglycaemic clamp to simulate the mean blood glucose $(11 \mathrm{mmol} / \mathrm{l})$ observed in the sucrose-fed diabetic rats. The insulin infusion rates were the same than those chosen in the sucrose-fed group.

In both groups, the steady-state plasma insulin level was reached $30 \mathrm{~min}$ after the beginning of insulin infusion, and the steady-state blood glucose level was reached $45-50 \mathrm{~min}$ after the beginning of insulin infusion. $200 \mu \mathrm{l}$ blood samples were collected at 50, 55 and $60 \mathrm{~min}$ to determine blood glucose specific activity and plasma insulin concentration. 
Table 1. Characteristics of high sucrose fed male diabetic rats

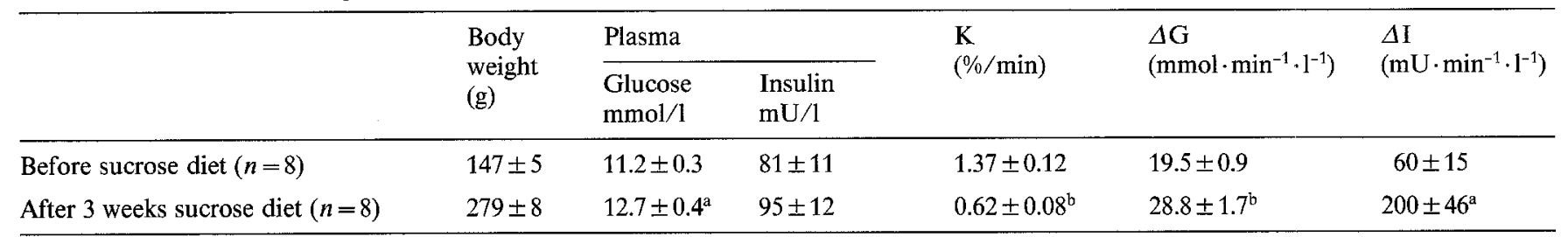

Values are expressed as mean $\pm \mathrm{SEM} ; \mathrm{n}=$ number of observations. $\mathrm{K}=$ rate of glucose disappearance; $\Delta \mathrm{G}=$ incremental integrated plasma glucose values; $\Delta \mathbf{I}=$ integrated plasma insulin values. ${ }^{\mathrm{a}} p<0.01 ;{ }^{\mathrm{b}} p<0.001$

\section{Endogenous glucose production}

Endogenous glucose production in the basal state as well as during each of the glucose clamp studies was assessed by a primed continuous infusion of $\left[3-{ }^{3} \mathrm{H}\right]$ glucose (New England Nuclear, Boston, Mass., USA). The labelled glucose was administered as an initial intravenous priming dose $(4 \mu \mathrm{Ci})$ followed immediately by a continuous intravenous infusion at a rate of $0.2 \mu \mathrm{Ci} / \mathrm{min}$. A steady-state of glucose specific activity was established by $40 \mathrm{~min}$ both in the basal state studies and in the clamp studies. The rate of glucose appearance ( $\mathrm{Ra}$ ) was then equal to the rate of glucose disappearance (Rd). These 2 parameters were calculated by dividing the $\left[3^{3} \mathrm{H}\right]$ glucose infusion rate $(\mathrm{dpm} / \mathrm{min})$ by the steady-state value of glucose specific activity $(\mathrm{dpm} / \mathrm{g})$. In the basal state the rate of endogenous glucose production is equal to the rate of glucose appearance (Ra). In the clamp studies, the rate of endogenous glucose production was calculated by substracting the exogenous glucose infusion rate from the rate of glucose appearance (Ra).

\section{Isolated pancreas perfusion technique}

The animals were anaesthetized with pentobarbital $(4 \mathrm{mg} / 100 \mathrm{~g}$ body weight intraperitoneally). Isolation and perfusion of the pancreas were performed as previously described [13]. The perfusate was a Krebs-Ringer bicarbonate buffer with the following components: $\mathrm{NaCl}, 118 \mathrm{mmol} / \mathrm{l} ; \mathrm{KCl}, 4 \mathrm{mmol} / 1 ; \mathrm{CaCl}_{2}, 2.5 \mathrm{mmol} / 1 ; \mathrm{MgSo}_{4}$, $1.2 \mathrm{mmol} / \mathrm{l} ; \mathrm{KH}_{2} \mathrm{PO}_{4}, 1.2 \mathrm{mmol} / \mathrm{l}, \mathrm{NaHCO}_{3}, 25 \mathrm{mmol} / 1$; fatty acidfree bovine serum-albumin, $1.25 \mathrm{~g} / 1$ (Sigma co, St Louis, Mo., USA); dextran $\mathrm{T} 70,40 \mathrm{~g} / 1$ (Pharmacia, Uppsala, Sweden). When needed, L-arginine (Sigma), D-glucose (Merck, Darmstadt, FRG) and acetyl$\beta$-methylcholine bromide (Sigma) were administered through a sidearm syringe. The complete effluent was collected from the cannula in the portal vein at $1 \mathrm{~min}$ intervals in chilled tubes and frozen for storage at $-20^{\circ} \mathrm{C}$ until assay.

\section{Analytical techniques and calculations}

Plasma glucose was determined using a glucose analyser (Beckman). Blood samples for determination of glucose specific activity were deproteinized with $\mathrm{Ba}(\mathrm{OH})_{2}-\mathrm{ZnSO}_{4}$ and immediately centrifuged. An aliquot of the supernatant was used for the determination of glucose concentration using a glucose oxidase method. Another aliquot of the supernatant was evaporated at dryness at $60{ }^{\circ} \mathrm{C}$ to remove tritiated water. The dry residue was dissolved in $0.2 \mathrm{ml}$ distilled water and counted with $10 \mathrm{ml}$ of Ready Solv-MP scintillation solution (Beckman). Plasma immunoreactive insulin was estimated using purified rat (studies in the basal state) or porcine (clamp studies) insulin as standards (Novo), antibody to mixed (porcine+bovine) insulin cross-reacting similarly with pork and rat insulin standards and porcine mono-iodinated ${ }^{125} \mathrm{I}$-insulin [12]. Charcoal was used to separate free from bound hormone. The method allows the determination of $6 \mathrm{mU} / 1(0.25 \mu \mathrm{g} / \mathrm{l})$ with a coefficient of variation within and between assays of $10 \%$.
The insulin and glucose responses during the glucose tolerance test were calculated as the incremental plasma insulin values integraded over the period $(30 \mathrm{~min})$ following the injection of glucose $\left(\Delta \mathrm{I}, \mathrm{mU} \cdot \mathrm{min}^{-1} \cdot \mathrm{l}^{-1}\right)$ and the corresponding incremental integrated plasma glucose values $\left(\Delta \mathrm{G}, \mathrm{mmol} \cdot \mathrm{min}^{-1} \cdot \mathrm{l}^{-1}\right)$. The rate of glucose disappearance $(\mathrm{K})$ was calculated from the slope of the regression line obtained with the log-transformed plasma glucose values between 5 and $30 \mathrm{~min}$ after glucose administration, and was expressed as $\% / \mathrm{min}$.

Insulin secretion rate per total pancreas was calculated by multiplying the insulin concentration in the samples by the flow rate and expressed as $\mu \mathrm{U} / \mathrm{min}$. Total insulin response to glucose, arginine and acetylcholine was obtained by planimetry of the individual perfusion profiles and expressed as the difference in hormonal secretion rate during the 20 -min stimulation ( $\Delta$ insulin, $\mu \mathrm{U} / \mathrm{min}$ ) relative to the mean hormonal output recorded at the end of the prestimulation period.

\section{Statistical analysis}

Results are given as mean \pm SEM. Statistical analysis was performed using Student's unpaired t-test. A $p$ value of $<0.05$ was considered statistically significant.

\section{Results}

\section{Effect of sucrose diet on glucose tolerance}

Feeding of sucrose diet over a 3-week period resulted in a significantly $(p<0.05)$ higher weight gain $(132 \pm$ $6 \mathrm{~g} / \mathrm{rat})$ than feeding the standard diet $(99 \pm 12 \mathrm{~g} / \mathrm{rat})$. The daily food intake was similar for sucrose-fed diabetic rats $(25.6 \pm 1.7 \mathrm{~g} / \mathrm{rat})$ and for chow-fed diabetic rats $(26.4 \pm 0.6 \mathrm{~g} / \mathrm{rat})$. In a pilot experiment performed with a batch of male diabetic rats maintained on the standard chow, it was determined that mean values for basal plasma glucose, incremental glucose area, $\mathrm{K}$ and incremental insulin area were not significantly different in 2.5 month old animals from those in 1.5 month old animals. As a consequence, values obtained in rats during sucrose feeding were compared to values in the same rats before sucrose feeding (Table 1). After 3 weeks on sucrose diet, the basal plasma glucose levels were significantly increased $(p<0.01)$. In response to intravenous glucose load, the mean incremental glucose areas were significantly increased $(p<0.001)$ and the $\mathrm{K}$ values were significantly decreased $(p<0.001)$ (Table 1). 


\section{Effect of sucrose diet on insulin secretion in vivo and in vitro}

In sucrose-fed diabetic rats, the basal plasma insulin after 3 weeks on the diet was not significantly affected. Values of the mean incremental insulin areas were multiplied by $3.3(p<0.01)$ (Table 1$)$, thus indicating that glucose-induced insulin secretion was increased in vivo, in sucrose-fed rats as compared to chow-fed rats. Concerning the insulin release in vitro from the isolated perfused pancreas under the basal condition, i.e. when perfusate did not contain glucose, the basal insulin release in the sucrose-fed rats was similar to that measured in the chow-fed rats. Exposure of the pancreases to glucose did not elicit any clear-cut increase of the insulin output in the chow-fed group, while some degree of insulin output was easily detected in

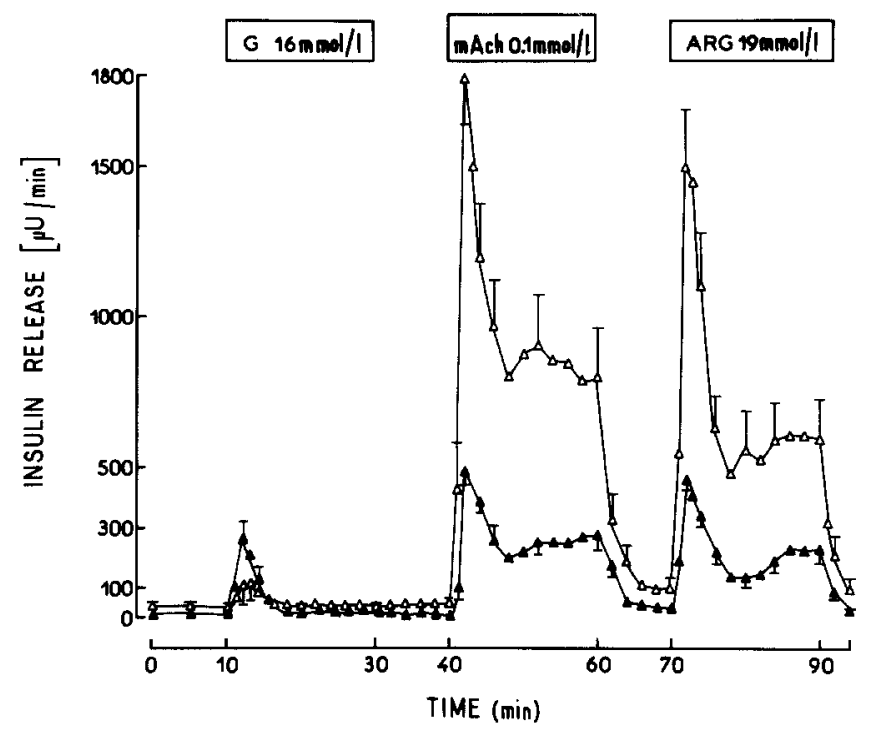

Fig. 1. Effect of $16 \mathrm{mmol} / \mathrm{l}$ glucose, $10^{-4} \mathrm{~mol} / 1$ methylacetylcholine (mAch) and $19 \mathrm{mmol} / \mathrm{L}$ arginine on insulin release from the perfused pancreas of chow-fed $(\Delta)$ and sucrose-fed ( $\Delta$ ) diabetic rats. These experiments were carried out in the absence of glucose during the pre- and post-stimulatory periods. Each point is the mean \pm SEM of 8 observations in each group the sucrose-fed rats. It was observed that the insulin response was under the form of a transient early peak of insulin release and that the sustained phase of insulin release was still lacking (Fig. 1 and Table 2). Such a tendency to higher insulin secretory response in sucrose-fed rats seems to be related specifically to stimulation by glucose, since it was not evoked by arginine or acetylcholine. More precisely, the insulin responses to arginine and to acetylcholine were significantly decreased $(p<0.01)$ in the sucrose-fed diabetic rats as compared to control diabetic rats (Fig. 1 and Table 2).

\section{Effect of sucrose diet on in vivo insulin action}

Basal rate of glucose production was significantly greater $(p<0.001)$ in sucrose-fed diabetic rats than in control diabetic rats (Table 3). During the hyperinsulinaemic clamp experiments, the blood glucose levels in chow-fed diabetic rats were clamped at values similar to those measured in the sucrose-fed diabetic rats (Table 3). Steady-state plasma insulin values (SSPI) reached with a $0.6 \mathrm{U} \cdot \mathrm{h}^{-1} \cdot \mathrm{kg}^{-1}$ or a $3.2 \mathrm{U} \cdot \mathrm{h}^{-1} \cdot \mathrm{kg}^{-1}$ in-

Table 2. Insulin secretory rates from the perfused pancreas of chow or high sucrose-fed diabetic rats. Basal release values were expressed as absolute values. Stimulated release values were calculated as the mean increase above basal release values

\begin{tabular}{|c|c|c|c|}
\hline & \multirow[t]{2}{*}{ Addition } & \multicolumn{2}{|c|}{ Insulin output $(\mu \mathrm{U} / \mathrm{min})$} \\
\hline & & $\begin{array}{l}\text { Chow fed } \\
(n=8)\end{array}$ & $\begin{array}{l}\text { High } \\
\text { sucrose fed } \\
(n=8)\end{array}$ \\
\hline $\begin{array}{l}\text { Basal } \\
\text { release }\end{array}$ & $\begin{array}{l}0 \mathrm{mmol} / 1 \\
\text { glucose }\end{array}$ & $19 \pm$ & $14 \pm 5$ \\
\hline \multirow{3}{*}{$\begin{array}{l}\text { Stimulated } \\
\text { release } \\
\text { (increase } \\
\text { above basal } \\
\text { release) }\end{array}$} & $\begin{array}{l}16 \mathrm{mmol} / 1 \\
\text { glucose }\end{array}$ & $13 \pm$ & $55 \pm 15$ \\
\hline & $\begin{array}{l}10^{-4} \mathrm{mmol} / 1 \\
\text { methylacetylcholine }\end{array}$ & $938 \pm 136$ & $259 \pm 33^{b}$ \\
\hline & $\begin{array}{l}19 \mathrm{mmol} / 1 \\
\text { arginine }\end{array}$ & $586 \pm 100$ & $201 \pm 32^{a}$ \\
\hline
\end{tabular}

Values are mean \pm SEM. $n=$ number of observations. ${ }^{\text {a }} p<0.01$ and ${ }^{\mathrm{b}} p<0.001$ as related to respective chow-fed groups

Table 3. Blood glucose, plasma insulin, glucose and insulin infusion rates and glucose kinetics during hyperinsulinaemic euglycaemic clamps in chow- or high sucrose-fed diabetic rats

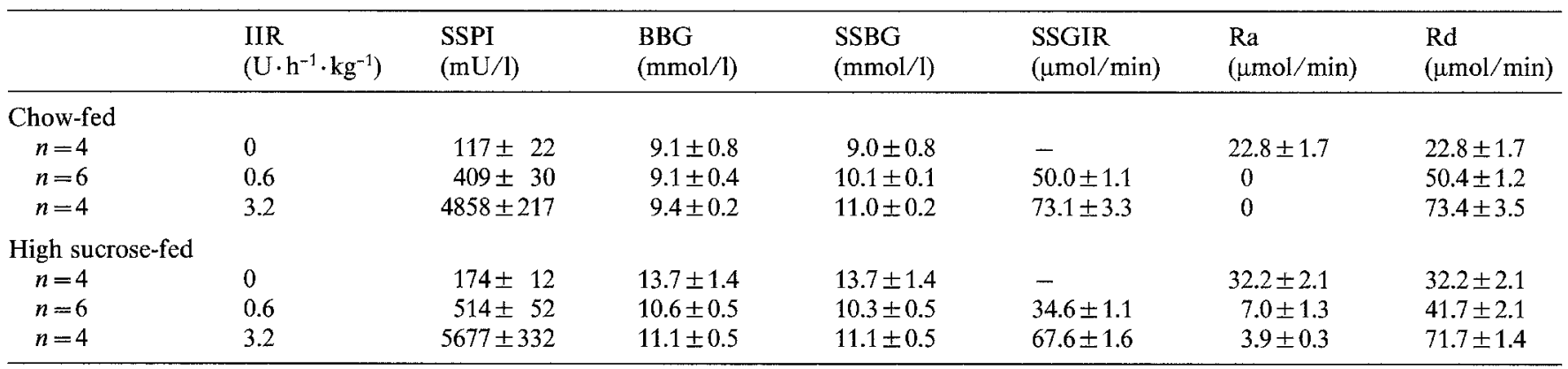

Values are mean \pm SEM; $\mathbf{n}=$ number of rats. IIR, insulin infusion rate; SSPI, steady-state plasma insulin; BBG, basal blood glucose; SSBG, steady-state blood glucose; SSGIR, steady-state glucose infusion rate; Ra, glucose production rate; $\mathrm{Rd}$, glucose utilisation rate 
sulin infusion were not significantly different from those in the sucrose-fed group infused with the corresponding insulin doses (Table 3 ).

Following a submaximal hyperinsulinaemia $(514 \pm 52 \mathrm{mU} / 1$ in the sucrose-fed group, $409 \pm 30$ in the control group) or following very high plasma insulin levels ( $5000 \mathrm{mU} / 1$ as a mean), endogenous glucose production was fully suppressed in the chow-fed group, while the values in the sucrose-fed group still remained significantly higher $(p<0.01)$ than the corresponding values in the chow-fed rats (Fig. 2 and Table 3). Basal rate of glucose utilization was significantly greater $(p<0.001)$ in sucrose-fed rats than in chow-fed rats (Table 3 ). Following a submaximal hyperinsulinaemia $(450 \mathrm{mU} / 1)$, the glucose utilisation in the sucrose-fed rats revealed significantly lower $(p<$ 0.01 ) than the corresponding utilization in the chowfed rats. Following a maximal hyperinsulinaemia $(5000 \mathrm{mU} / 1$, the glucose utilisation was similar in both groups (Fig. 2 and Table 3).

\section{Discussion}

In the diabetic rats, the high sucrose diet used in the present study leads to greater weight gain than the standard diet. It increases the basal plasma glucose levels and deteriorates modestly the glucose tolerance as attested by $\mathrm{K}$ values significantly lower as compared to control values. This was observed despite an increase of the in vivo insulin response to an intravenous glucose load. This adverse long-term (1 month) effect of a high sucrose diet on the glucose homeostasis of rats with non-insulin-dependent diabetes is in accordance with previous observations. In streptozotocin-diabetic rats, it has been reported that a 1 month high sucrosefeeding deteriorated both basal glycaemia and glucose tolerance $[9,15]$. Conversely, long-term (10 months) low carbohydrate diet, regardless of fat or protein content, reduced basal hyperglycaemia and daily glycosuria [41]. Our report that high sucrose diet increases body weight in rats with non-insulin-dependent diabetes is also consistent with the observation by Hallfrisch et al. [15] indicating that perirenal fat deposits and body weight after sucrose feeding were higher in midly diabetic rats (but such a response to the diet was no longer seen in rats with more severe streptozotocin diabetes). The present conclusions in insulin-deficient rats are in fact opposite to those reported in normal rats both by us using the same diet protocol [22] and by others $[10,26,43]$, indicating that glucose tolerance was ameliorated with a high sucrose diet.

Our results indicate that the increased insulin secretion in response to glucose in vivo is in fact related to a slight increase in pancreatic $\mathrm{B}$ cell reactivity to glucose per se, since it is still observed with the isolated perfused pancreas preparation. From the qualitative point of view, this is in accordance with previous observa-

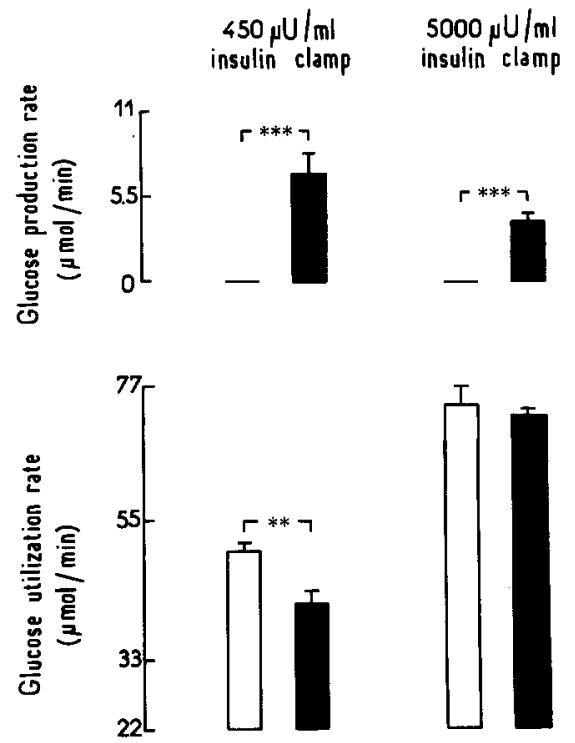

Fig. 2. Glucose production and glucose uptake during insulin-glucose clamps in chow-fed $(\square)$ and in sucrose-fed ( $\square$ ) diabetic rats. These experiments were performed at basal, submaximal $(450 \mathrm{mU} / \mathrm{l})$ and maximal $(5000 \mathrm{mU} / 1)$ steady-state plasma insulin concentrations. The height of the bar represents the mean \pm SEM for each groups. The number of observations in the groups was from 4 to 6 . ${ }^{* *} p<0.01 ;{ }^{* * *} p<0.001$

tions in the normal rat after sucrose feeding [22, 24]. The mechanism involved in the insulin output by the pancreases of sucrose-fed diabetic rats remains presently unknown, as the total pancreatic insulin content remained unaffected as compared to chow-fed diabetic rats (unpublished results). Nevertheless, it appears characteristic that the increase in insulin release is found only after glucose stimulation, since the same pancreases of sucrose-fed rats exhibited significantly lower $(p<0.01)$ response to arginine and to acetylcholine. This decreased insulin response to acetylcholine was also found in normal rats after sucrose feeding [22]. From a variety of experimental studies it is acknowledged that the cholinergic system plays an important role in the regulation of insulin secretion [28]. More closely related to our present observations in the sucrose-fed rat, whether normal or diabetic, should be the results of Campfield et al. [5]. They suggest that the interruption of vagal input to pancreatic $B$ cell by vagotomy in the rat induces a decreased sensitivity to acetylcholine and an increased glucose responsiveness. Thus, one may speculate that sucrose feeding determines changes in parasympathetic neural input to the pancreas which are similar to those observed after subdiaphramatic vagotomy.

Our present data indicate that a 1-month sucrose diet significantly deteriorates the glucose tolerance in the rat with non-insulin dependent diabetes; the $\mathrm{K}$ value was significantly lower as compared to control value, suggesting decreased insulin action. However, the relationship between the $\mathrm{K}$ value and the efficiency of 
insulin on glucose-uptake is not a direct one. In order to obviate interpretation difficulties, we have investigated this question of insulin action in sucrose-fed rats using the insulin-glucose clamp technique in conjunction with isotopic measurement of glucose turnover. During the clamp experiments performed at similar blood glucose levels in both groups, the rates of exogenous glucose infusion (SSGIR, Table 3 ) required to maintain blood glucose at glycaemia of sucrose-fed diabetic rats at steady-state plasma insulin are taken as a measure of the effect of insulin on total-body glucose metabolism. Under the present experimental conditions, these infusion rates are equal to the sum of the decrement in glucose production and the increment of glucose utilisation caused by insulin. As shown in Table 3, total-body glucose metabolism in sucrose-fed rats is significantly lower from that in chow-fed rats at submaximal insulin levels, but it is similar at maximal insulin levels. This last observation indicates that the total-body glucose metabolism is less sensitive to insulin in sucrose-fed diabetic rats as compared to controls. However, such a parameter does not indicate whether the insulin responsiveness of glucose-producing or glucose-utilizing tissues is modified in sucrose-fed rats.

The basal glucose utilisation was found significantly higher in sucrose-fed rats. During the clamp studies the glucose utilisation induced by submaximal insulin level was significantly less important in the sucrose-fed rats than in the chow-fed rats, but at the maximal insulin level glucose utilisation was found similar in both groups. These data suggest that insulinmediated glucose uptake in the sucrose-fed diabetic rats is decreased only over the range of submaximal plasma insulin levels. Such a conclusion in diabetic rats is opposed to our recent observation [22] that the same sucrose diet induces an ehanced insulin-mediated glucose uptake in non-diabetic rats. In an attempt to explain this discrepancy, it may be remembered that rats with non-insulin-dependent diabetes respond to high sucrose diet with a very limited enhancement of insulin output (as compared to non-diabetic rats). In normal or obese rats, it has been shown that the relatively chronic hyperinsulinaemia induced by high sucrose feeding leads in isolated adipocytes to increased insulin responsiveness of glucose transport, glucose oxidation and lipogenesis $[23,29,30,39]$. By contrast, in the adipocytes of severely diabetic rats (unable to enhance their insulin output during exposure to the sucrose diet) glucose metabolism remained unresponsive to insulin during sucrose feeding [39]. This indicates that sucrose diet leads to enhanced cellular responsiveness to insulin, provided the animal can respond to the diet with prominent increase of insulin release; otherwise, as is probably the case in rats with non-insulindependent diabetes, a state of relative insulin resistance develops. Nevertheless, one may recall that sucrose-fed diabetic rats gained more weight than diabetic rats on standard chow. Thus, adaptation to obesi- ty could contribute to the development of insulin resistance.

One of the aims of the present study was to evaluate the effect of insulin on endogenous glucose production in sucrose-fed diabetic rats. As rats from both groups were in the post-absorptive state, one can assume that the rate of glucose production measured in the present study represents hepatic glucose production. In the basal state, hepatic glucose production was higher in sucrose-fed rats than in chow-fed rats. The factors responsible for maintaining this elevated rate of basal hepatic glucose production remain to be identified. This could be at first glance a reflection of an hepatic insulin resistance, since the liver of sucrose-fed rats was in fact resistant to submaximal and maximal insulin levels. This last notion is based on the fact that, during the clamp studies, the suppression of glucose production induced by submaximal or maximal insulin levels was significantly less effective in the sucrose-fed rats than in the controls (Fig.2, Table 3). Such a conclusion in rats with non-insulin-dependent diabetes is similar to that recently reported by us in non-diabetic rats fed the same sucrose diet [22]. We are not aware of any study concerning the in vivo insulin action in the liver of sucrose-fed animals. Nevertheless, it has been observed in sucrose-fed non-diabetic animals, that glucose-6-phosphatase activity was substantially elevated [11]. This pattern was also associated with simultaneous stimulation of glycolytic and lipogenic enzymes. As, in contrast to glucose, the bulk of dietary fructose must be metabolized by the liver [17], the metabolism of fructose through fructose-1-phosphate increases the flow of triose phosphate intermediates to glycolysis [4] and augments the flow of hexose phosphate in the opposite pathway (gluconeogenesis). Moreover, the increased activity of glucose-6-phosphatase would be expected to reduce the overall rate of glucose phosphorylation, and thus interfere with the hepatic glucose uptake. Indeed, deficient hepatic glucose utilisation has been demonstrated in sucrose-fed non-diabetic rats [18], and more recently it has been reported that the ability of insulin to suppress glucose outflow is less in perfused livers from fructose-fed rats at submaximal and maximal insulin levels [42].

In conclusion, the current results indicate that chronic sucrose-feeding in rats with diabetes leads to a significant deterioration of glucose tolerance. Furthermore, they provide direct evidence that this impairment results from two additive changes in insulin's effect upon the target tissues: the insulin-mediated glucose uptake by peripheral tissues is decreased, and the liver becomes resistant to insulin action due to a diminished ability of insulin to suppress hepatic glucose output.

Finally, these results suggest that high sucrose (instead of complex carbohydrate) feeding in rats with diabetes can lead to metabolic events likely to develop insulin resistance in target tissues. Such a pattern is di- 
rectly related to the insulin-deficient state in these rats, since the same sucrose diet induces an enhanced insulin-mediated glucose uptake in non-insulin-deficient animals [22].

Acknowledgments. We are grateful to Professor L. Picon for stimulating discussions, to Drs R.Aubert and D.Lemonnier (INSERMUnite 1-Paris) for the supply of semi-synthetic diets, and to Drs E. Forgue-Laffitte and G. Rosselin (INSERM-Unite 55-Paris) for the supply of iodinated insulin. This work was supported by the Institut National de la Santé et de la Recherche Médicale (INSERM) (CRE no. 847011). M.K. is a recipient of a fellowship from the Fondation pour la Recherche Médicale (Paris, France)

\section{References}

1. American Diabetes Association (1984) Principles of nutrition and dietary recommandations for individuals with diabetes. Diabetes Care 7: 607-608

2. Bantle JP, Laine DC, Castle GW, Thomas JW, Hoogwerf BJ and Goetz FC (1983) Postprandial glucose and insulin responses to meals containing different carbohydrates in normal and diabetic subjects. N Engl J Med 309: 7-12

3. Bornet F, Haardt MJ, Costagliola D, Blayo A and Slama G (1985) Sucrose or honey at breakfast have no additional acute hyperglycaemic effect over an isoglucidic amount of bread in type 2 diabetic patients. Diabetologia 28: 213-217

4. Burch HB, Lowry OH, Meinhardt L, Max Jr P and Chyn KS (1970) Effect of fructose, dihydroxy-acetone, glycerol and glucose on metabolites and related compounds in liver and kidney. $\mathbf{J}$ Biol Chem 245: 2092-2096

5. Campfield LA, Smith FJ and Eskinazi RE (1984) Glucose responsiveness and acetylcholine sensitivity of pancreatic B-cells after vagotomy. Am J Physiol 246: R985-R993

6. Chantelau EA, Gösseringer G, Sonnenberg GE and Berger M (1985) Moderate intake of sucrose does not impair metabolic control in pump-treated diabetic out-patients. Diabetologia 28: 204-207

7. Cherrington AD, Williams PE and Harris MS (1978) Relationship between the plasma glucose level and glucose uptake in the conscious dog. Metab Clin Exp 27: 787-791

8. Cohen AM and Teitelbaum A (1964) Effect of dietary sucrose and starch on oral glucose tolerance and insulin-like activity. Am J Physiol 206: 105-108

9. Dall'Aglio E, Chang F, Chang H, Wright D and Reaven G (1983) Effect of exercise training and sucrose feeding on insulin-stimulated glucose uptake in rats with streptozotocin-induced insulindeficient diabetes. Diabetes 32: 165-168

10. Eaton RP and Kipnis DM (1969) Effects of high-carbohydrate diets on lipid and carbohydrate metabolism in the rat. Am J Physiol 217: 1160-1165

11. Fitch WM and Chaikoff IL (1960) Extent and patterns of adaptation of enzyme activities in livers of normal rats fed diets high in glucose and fructose. J Biol Chem 235: 554-559

12. Freychet $P$, Roth J and Neville DM (1971) Monoiodoinsulin: demonstration of biological activity and binding to fat cells and liver membranes. Biochem Biophys Res Commun 43: 400-408

13. Giroix MH, Portha B, Kergoat M, Bailbe D and Picon L (1983) Glucose insensitivity and amino-acid hypersensitivity of insulin release in rats with non-insulin-dependent diabetes. A study with the perfused pancreas. Diabetes 32: 445-451

14. Gottesman I, Mandarino L and Gerich J (1984) Use of glucose uptake and glucose clearance for the evaluation of insulin action in vivo. Diabetes 33: 184-191

15. Hallfrisch J, Lazar FL and Reiser S (1979) Effect of feeding sucrose or starch to rats made diabetic with streptozotocin. J Nutr 109: 1909-1915
16. Hallfrisch J, Lazar FL, Jorgensen C and Reiser S (1979) Insulin and glucose responses in rats fed sucrose or starch. Am $\mathbf{J}$ Clin Nutr 32: 787-793

17. Hers HG (1955) The conversion of fructose- $1-{ }^{14} \mathrm{C}$ and sorbitol $1{ }^{14} \mathrm{C}$ to liver and muscle glycogen in the rat. J Biol Chem 214: 373-375

18. Hill R, Balzer N, Chaikoff IL (1954) Altered metabolic patterns induced in the normal rat by feeding an adequate diet containing as sole carbohydrate. J Biol Chem 209: 705-709

19. Kanarek RB and Marks-Kaufman R (1979) Developmental aspects of sucrose-induced obesity in rats. Physiol Behav 23: $881-885$

20. Kanarek R and Orthen-Gambill N (1982) Differential effects of sucrose, fructose and glucose on carbohydrate-induced obesity in rats. J Nutr 112: 1546-1554

21. Kergoat $M$ and Portha B (1985) In vivo hepatic and peripheral insulin sensitivity in rats with non-insulin-dependent diabetes induced with streptozocin. Assessment with the insulin-glucose clamp technique. Diabetes 34: 574-579

22. Kergoat M, Bailbé D and Portha B (1987) Effect of high sucrosediet on the insulin secretion and insulin action. A study in the normal rat. Diabetologia 30: 252-258

23. Kobayashi M and Olefsky JM (1978) Effect of experimental hyperinsulinemia on insulin binding and glucose transport in isolated rat adipocyte. Am J Physiol 235: E53-E62

24. Laube $H$, Schatz $H$, Nierle $C$, Fussgänger $R$ and Pfeiffer EF (1976) Insulin secretion and biosynthesis in sucrose fed rats. Diabetologia 12: $441-446$

25. Laube H, Wojcikowski C, Schatz H and Pfeiffer EF (1978) The effect of high maltose and sucrose feeding on glucose tolerance. Horm Metab Res 10: 192-195

26. Lin W and Anderson JW (1977) Effects of high sucrose or starch bran diets on glucose and lipid metabolism of normal and diabetic rats. J Nutr 107: 584-595

27. Maegawa $H$, Kobayashi $M$, Ishibashi $O$, Takata $Y$ and Shigeta $Y$ (1986) Effect of diet change on insulin action: difference between muscles and adipocytes. Am J Physiol 251: E616-E623

28. Miller RE (1981) Pancreatic neuroendocrinology: peripheral neural mechanisms in the regulation of the islets of Langherans. Endocrine Rev 2: 471-494

29. Oka Y, Akanuma Y, Kasuga M and Kosaka K (1980) Effect of a high glucose diet on insulin binding and on insulin action in rat adipocytes. Diabetologia 19: 468-474

30. Olefsky JM and Saekow M (1978) The effects of dietary carbohydrate content on insulin binding and glucose metabolism by isolated rat adipocytes. Endocrinology 103: 2252-2263

31. Osei K, Falko JM, Fields PG, Bossetti B and O'Dorisio TM (1986) The effects of carbohydrate-enriched meals on glucose turnover and metabolic clearance rates of glucose on type 2 diabetic patients. Diabetologia 29: 100-105

32. Peterson DB, Lambert $\mathbf{J}$, Gerring $\mathrm{S}$, Darling $\mathrm{P}$, Carter RD, Jelfs R and Mann JI (1986) Sucrose in the diet of diabetic patients. Just another carbohydrate? Diabetologia 29: 216-220

33. Portha B, Levacher C, Picon L and Rosselin G (1974) Diabetogenic effect of streptozotocin in the rat during the perinatal period. Diabetes 23: $889-895$

34. Portha B, Picon L and Rosselin G (1979) Chemical diabetes in the adult rat as the spontaneous evolution of neonatal diabetes. Diabetologia 17: 371-377

35. Portha B, Giroix MH and Picon L (1982) Effect of diet on glucose tolerance and insulin response in chemically diabetic rats. Metabolism 21: 1194-1199

36. Rattigan S and Clark MG (1986) Effect of sucrose feeding on insulin-mediated glucose transport in adipocytes and soleus muscle of the rat. Nutr Rep Int 33: 225-234

37. Reiser $S$ and Hallfrisch $J$ (1977) Insulin sensitivity and adipose tissue weight of rats fed starch or sucrose diets and libitum or in meals. J Nutr 107: 147-155

38. Romsos DR and Leveille GA (1974) Effect of meal frequency and diet composition on glucose tolerance in the rat. J Nutr 104: 1503-1512 
39. Saekow M and Olefsky JM (1980) Effect of high carbohydrate diet on adipocyte glucose metabolism in spontaneously obese rats and insulin deficient diabetic rats. Endocrinol 107: 2004-2010

40. Salans LB, Foley JE, Wardzala LJ and Cushman SW (1981) Effects of dietary composition on glucose metabolism in rat adipose cells. Am J Physiol 240: E175-E183

41. Schmidt FH, Siegel EG and Trapp VE (1980) Metabolic and hormonal investigations in long term streptozotocin diabetic rats on different dietary regimens. Diabetologia 18: 161-168

42. Tobey TA, Mondon CE, Zavaroni I and Reaven GM (1982) Mechanism of insulin resistance in fructose-fed rats. Metabolism 31: $608-612$

43. Vallerand AL, Lupien J, Bukowiecki LJ (1986) Synergistic improvement of glucose tolerance by sucrose feeding and exercise training. Am J Physiol 250: E607-E614
44. Wright DW, Hansen RI, Mondon CE and Reaven GM (1983) Sucrose-induced insulin resistance in the rat: modulation by exercise and diet. Am J Clin Nutr 38: 879-883

Received: 20 March 1987

and in revised form: 19 June 1987

Dr. Bernard Portha

Laboratoire de Physiologie du Developpement

Université Paris 7

Tour 54, 4 ème étage

2 Place Jussieu

F-75251 Paris Cedex 05

France 